\title{
Infrastructure delivery and spatial planning The case of English Local Development Frameworks
}

\begin{abstract}
This paper examines the delivery of infrastructure requirements related to the plan-making (LDF) process in England introduced as part of the 2004 planning system reforms. Success or otherwise in terms of plan implementation and infrastructure delivery is crucial if the reformed spatial planning system is to be successful. The paper draws on research undertaken as part of a government-sponsored research project into the operation of the new LDF process. The research reveals a significant gap between government expectations and current practice. It suggests that longer-term commitments by central government, alongside improved understanding of the spatial planning process and the role of local government as part of a continued drive for 'culture change' among local planning authorities and delivery partners, will be required if the current barriers to the delivery of infrastructure are to be overcome. Otherwise, the new-style LDFs are as likely to be plagued by implementation gaps as were their predecessors.
\end{abstract}

Planning has long been criticised for its failure to implement plans and policies effectively (Talen, I996a; Rydin, 2003). One of the most significant barriers facing the implementation of plans is the delivery of the infrastructure needed to support development (Netzer, I992). At the end of the I99os, the inability of the land-use planning system to deliver infrastructure was identified as one of the key constraints on economic development in the UK (CBI and TUC, 200I). It was this criticism, among others, that led to the 2004 Planning and Compulsory Purchase Act. This prompted a radical new approach to planning in England and 'marked the beginning of a new era of developing spatial rather than purely land-use plans' (Baker and Wong, 2006, 66r). In terms of the requirements of the new system, the implementation of plans and the delivery of infrastructure have subsequently been significantly strengthened through Local Development Frameworks (LDFs) and emerging policy guidance and regulation. However, a key issue that remains is the need to understand the reality of undertaking infrastructure delivery under the requirements of the new planning system and to understand what opportunities and challenges face policymakers in the delivery of infrastructure. This is an important line of inquiry given the emphasis that the government is placing on reducing barriers to development, particularly those related to the delivery of housing and infrastructure (ODPM, 2003; Barker, 2004; 2006).

Drawing on research undertaken for the Spatial Plans in Practice project (SPiP), a

Mark Baker is a Senior Lecturer in Planning Policy and Practice and Stephen Hincks is a Research Associate in the Centre for Urban Policy Studies (CUPS), Planning and Landscape, School of Environment and Development, University of Manchester, Oxford Road, Manchester, Mi3 9PL; email: mark.baker@manchester.ac.uk and stephen. hincks@manchester.ac.uk

Paper submitted August 2008; revised paper received April 2009 and accepted May 2009. 
major three-year study of the new local planning system in England funded by central government, this paper aims to add to the existing evidence base on plan implementation by reporting the findings of a study into the practical matters related to the delivery of infrastructure as part of the implementation of LDFs in England. The next section establishes the background related to plan implementation and infrastructure delivery and this is followed by a review of the current planning policy context underpinning the delivery of infrastructure in England. The third section briefly identifies a series of research questions that underpin the subsequent empirical investigation into the practice of infrastructure delivery within England and outlines the research methodology employed, which involves several interlinked components, including documentary reviews of adopted core strategies $(\mathrm{CSs})$ and area action plans (AAPs); local case studies covering a number of different planning contexts in which infrastructure delivery is a significant issue; and workshops with key stakeholders and delivery partners. The main findings from each of these components are reported in the subsequent sections of the paper and are used to address the initial research questions. The final section reflects further on these as well as outlining some general policy recommendations designed to facilitate more effective infrastructure delivery and LDF implementation in England.

\section{Planning, plan implementation and infrastructure delivery}

The implementation of plans was generally given a low priority in 'front-line' planning departments. Even in the 'early post-war era ... the plan chests of many local planning authorities were stuffed with "bottom-drawer" plans that had not been through the practical, messier business, of implementation' (Taylor, I998, in I). In a critique of rational planning in the late ig6os, Friedmann (I969, 3I I) contended that 'society has been planning too much and experiencing far too little application of plans'. In the period following Friedmann's critique of the failure of rational planning to deal effectively with the implementation issue, the field of policy implementation was launched with the publication of Pressman and Wildavsky's (I973; I984) seminal text, Implementation. This led to a proliferation of studies in a number of areas of public policy such as the implementation of economic, social and health policies (Berke et al., 2006), particularly notable in a British context being Barrett and Fudge's (I98I) volume on policy implementation in a number of policy areas which took a bottom-up, policydriven approach (Healey, I997). In the case of planning, it stimulated a debate about the nature of the planning process and the evaluation of plan implementation (see Alexander and Faludi, I989).

The opening shot in this particular debate was fired by Wildavsky (I973), who raised the possibility that 'if planning is everything, maybe it's nothing'. His intention was to make a demonstrable link between the nature and definition of planning and 
the process of evaluation. He defined planning as 'control of the future' and argued that, because uncertainty makes control of the future impossible, then answering the question 'what is good or bad planning?' is impossible. This implies that anything other than total conformity between a plan's stated objectives and the subsequent outcomes on the ground is a failure of implementation. This view has been rejected as being too extreme and misrepresentative of the nature of planning (Alexander, I98I; Faludi, I987). However, it was acknowledged that Wildavsky's shot across the bows nevertheless raised important questions as to the nature of planning and the related problem of how planning outcomes, and plan implementation, can be evaluated (Alexander, I98I).

Many of the subsequent evaluation studies in planning have focused on determining the quality of plans and have attempted to evaluate the impact of particular plan-making practices on plan quality (Berke et al., 2006). However, more recently the evaluation literature has increasingly focused on developing new methods for evaluating and appraising plan implementation (Alexander and Faludi, I989; Talen, I996b; Baer, I997; Laurian et al., 2004; Berke et al., 2006). This is a response to the fact that planners have been unable to effectively assess the success or failure of plans because of a paucity of methods available to allow for systematic analysis of plan implementation (Laurian et al., 2004). Developing the capacity to evaluate plan implementation through empirical testing is an important endeavour given that, to date, the absence of an effective method for evaluating plan implementation has meant that 'comments by planners and theorists on the success or failure of plans rely on assumptions rather than empirical assessments' (Laurian et al., 2004, 47I).

Nonetheless, the need to understand the practices, processes and issues underpinning plan implementation is equally important. There have been some attempts to make a direct link between policy implementation theory and planning practice (e.g. Pountney and Kingsbury, I983a; I983b; Healey, I983) and a limited number of studies exploring the processes, practices and issues involved in the implementation of physical and spatial plans (Berke et al., 2006). Overall, however, an important opportunity has been missed, given that the context of the implementation process provides important insights into the way that policy intentions are translated into a plan (plan content) and subsequently delivered on the ground (Gilg and Kelly, ig97a).

Past research demonstrates that plan implementation is structured by a process of negotiation and interaction between different stakeholders, many of whom have different interests and agendas (Healey et al., I988; McDonald, I989; Healey, I997). It also highlights the fact that political and institutional structures (Alterman and Hill, I978), plan quality and enforcement style (Berke et al., 2006), and levels of finance to fund delivery (Bridges, I99I) affect the implementation of a plan. More often than not, the result of these contextual factors is the emergence of a plan implementation 'gap' - a discrepancy between what plans are intended to deliver and what they actually 
deliver (Cloke, I987). A number of studies have identified implementation gaps in the UK (Gilg and Kelly, r997a; i997b), Canada (Filion, I996), New Zealand (Laurian et al., 2004; Berke et al., 2006), and the US (Dalton, I989; Burby et al., I997).

One of the main criticisms of planning systems is the lack of coordination in the delivery of necessary infrastructure to support proposed development (Netzer, I992; Ennis, 2003a; Webber and Marshall, 2007). Ennis (2003a) argues in the British context that this lack of coordination reflects the historic evolution of changing infrastructure delivery practices that began with nationalisation of utilities in the post-war period and, later, the privatisation of utilities, water and sewage in the ig8os. As a result, the gap between infrastructure providers and local planning authorities has steadily grown and local influence in infrastructure provision has declined. Research highlights that the liberalisation and commercialisation of infrastructure delivery continues to affect the provision of 'hard' infrastructure such as electricity, gas and water supply, sewage disposal, and telecommunications (Graham and Marvin, i996; Guy et al., ı997; Graham, 2000). However, Ennis (2003a) also highlights the importance of providing 'soft' infrastructure such as community centres, schools, recreation facilities and green space in order to deliver well functioning local areas.

The implication of this liberalisation and privatisation of the provision of infrastructure is detailed by Moss (2003) in a study of infrastructure delivery practices in Berlin. He differentiates between infrastructure 'hot-spots' (areas where demand is high and at risk of exceeding capacity) and 'cold-spots' (areas where demand is low and stagnating). Several commentators have previously highlighted that there is a distinct spatial dimension to these areas of differentiated supply of, and demand for, infrastructure (e.g. Guy et al., I997; Graham, 2000). Moss (2003) suggests that hot and cold spots form as a result of the delivery practices of providers as dictated by financial incentives. The study found that service providers would create demand in those areas that were the most economically viable, while only delivering the minimum contractual or legal levels of provision to areas that were considered economically unviable. In addition to the practices of providers, infrastructure delivery has also been shown to be dependent on the ability of planning authorities, often through weak and tenuous networks, to negotiate the delivery of infrastructure with delivery providers (see Ennis, $2003 \mathrm{~b}$ ), for all parties to overcome the politics involved in the process of negotiation (Bianco and Adler, 200i; Flyvbjerg, 2007), and for local planning authorities to secure sufficient financing for necessary infrastructure projects (e.g. Campbell et al., 200o; Verhage and Needham, 2003; Webber and Marshall, 2007).

Given that practitioners question the value of plan-making when the issues and proposals identified in the plan are not subsequently acted upon (Berke et al., 2006), it seems logical to identify ways to improve plan implementation. However, given the inability of quantitative techniques to get fully behind the implementation process, it is important that evaluation and monitoring exercises are complemented by a 
concerted effort to improve the processes and practices supporting the plan implementation process (Gilg and Kelly, I997a). Improving the links between emerging plans and the subsequent delivery of the necessary infrastructure required by the development proposals and policies set out in these plans was consistently highlighted in the government's 2004 planning system reforms. The next section of this paper therefore maps out the current planning policy context that underpins the delivery of infrastructure in England.

\section{Infrastructure delivery and the implementation of Local Development Frameworks in England}

At the beginning of the 200os, the CBI-TUC Investment Group (200I) raised concerns that the British planning system was failing to deliver with the speed and responsiveness needed by businesses; a key element of their criticism was directed at the failure of the system to deliver the infrastructure needed for businesses to function competitively (Nadin, 2007). The 200 I Planning Green Paper (DLTR, 200i; Rozee, 2008, 596-7) marked the formal start of the process of reform of the planning system in England with a critique of the various failings of the existing system. Most significantly for the context of this paper, these failings included serious issues of timescales and delay in the plan-making process and subsequent failures in the delivery and

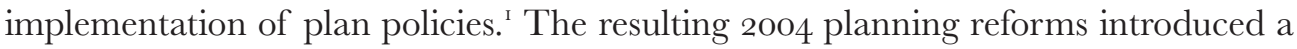
new 'spatial planning' approach which 'goes beyond traditional land use planning to bring together and integrate policies for the development and use of land with other policies and programmes which influence the nature of places and how they can function' (ODPM, 2005, para. 30).

The LDFs that lie at the heart of the 2004 Planning Act approach 'include policies which can impact on land use ... but which are not capable of being delivered solely or mainly through the granting or refusal of planning permission and which may be implemented by other means' (ODPM, 2005, para. 30). Such an approach demands the identification of the means of implementation and this was reflected in one of the identified tests of 'soundness', which requires 'clear mechanisms for implementation and monitoring' (ODPM, 2004, para. 4.24), that plans have to satisfy before they can be cleared for adoption by the Planning Inspectorate following a public examination. Consequently, the new spatial planning system is about more than just plan-making process and procedures; it is also about ensuring the implementation of plans, in a coordinated and integrated way, in line with the principles of sustainable development (ODPM, 2005, para. 6).

I The reform of the English planning system enacted in the Planning and Compulsory Purchase Act 2004 was part of wider reforms to the planning system (Rozee, 2008). 
This emphasis on the implementation of spatial plans, and the links between plans and infrastructure delivery, has been further highlighted and strengthened through the new system. As the 2004 version of Planning Policy Statement I2 (PPSI2) stated, 'the provision of infrastructure is important in all major new developments. The capacity of existing infrastructure and the need for additional facilities should be taken into account in the preparation of all local development documents' (ODPM, 2004: Annex B, para. 3). Similarly, concern over the responsiveness of the planning system to questions of housing supply prompted the government to commission the Barker Review of Housing Supply (Barker, 2004). The Barker Review identifies a number of infrastructure-related barriers to housing supply, including a lack of existing infrastructure to support new housing development; local authority fears that new housing development will place unsustainable pressures on existing infrastructure; and the underresourcing of infrastructure to accommodate new housing provision. In response, the government commissioned a second 'Barker Review' into land use planning (Barker, 2006) in which it is argued that the planning system is inefficient and unresponsive and that necessary infrastructure is not being delivered quickly enough.

Against this backdrop, the government (in conjunction with the RTPI) commissioned research exploring Effective Practice in Spatial Planning (EPiSP) (UCL and Deloitte, 2007). This report contains important insights into the role of spatial planning as 'a delivery vehicle for the social, economic and environmental infrastructure needed for our communities' (UCL and Deloitte, 2007, 5). The report makes recommendations for alternative and innovative approaches for the delivery of infrastructure. These include improved collaboration between planners and the stakeholders involved in Local Strategic Partnerships (LSPs) and the potential use of delivery mechanisms such as Local Area Agreements (LAAs) and Multi-Area Agreements (MAAs) to deliver infrastructure projects. It also recommends that local planning authorities establish a local infrastructure programme, together with a local infrastructure fund, managed by a local infrastructure group to improve coordination of infrastructure delivery and to facilitate more effective resource management. In essence, the EPiSP report calls for the strengthening of local influence in the infrastructure delivery process. This view had been supported in the Local Government White Paper (DCLG, 2006) which argues that, if development and infrastructure provision are to take place or incentive effects are to be realised, then there needs to be a transparent and predictable link between local development and local resourcing.

The Planning White Paper (DCLG, 2007a) pulls many of these strands together, setting out proposals for a forward-looking approach to infrastructure provision at the local level that moves away from 'site specific planning of infrastructure delivery to a more strategic and holistic view, which takes infrastructure decisions on roads alongside those of, for example, schools, hospitals, cultural and community facilities' (DCLG, 2007a, para. 8.26). It identifies local authorities as 'the right bodies to be undertaking 
this strategic view of infrastructure provision at the local level' (para. 8.27). However, it states that, in doing so, they 'will need to involve infrastructure providers ... and may well need to work across local authority boundaries'. Thus, local authorities are effectively identified as the 'ring-masters' working with other providers and stakeholders to coordinate local infrastructure provision. The LDF's role is further highlighted in the White Paper through proposals to clarify the existing soundness test on 'implementation' so that local authorities more clearly 'demonstrate how and when infrastructure that is required to facilitate development will be delivered' (para. 8.28).

This brief discussion demonstrates that, from a policy perspective, increasing emphasis is being placed on improving the efficiency of the planning system so that it is better placed to deal with the delivery of infrastructure. However, regulation and guidance can only go so far. The delivery of infrastructure is dependent on the actual processes and practices being simultaneously played out locally up and down the country as part of the preparation and implementation of LDFs. With this in mind, the remainder of this paper explores some of the lessons and realities of current practice in delivering infrastructure requirements within the context of preparing and implementing LDFs. In doing so, it continues to explore some of the opportunities and challenges facing planners and policymakers in undertaking this task.

\section{Methodology}

This relatively brief review of previous academic literature and recent policy contexts to plan-making and implementation in England following the 2004 reforms raises a number of questions that will be addressed in the remainder of the paper:

I. To what extent are the emerging plans (LDF documents) in the new spatial planning system adequately addressing the future delivery of infrastructure and plan implementation?

2. Is there evidence of a continuing 'gap' in the implementation of these new-style plans?

3. To what extent is there evidence that failures in the current practices and mechanisms available to local planning authorities to secure the required delivery of infrastructure are fostering such implementation gaps?

4. If so, how might such plan implementation gaps in the delivery of the new-style plans be 'filled' by more effective local planning practices; better collaboration between stakeholders and delivery partners; and/or central government intervention (e.g. in terms of both national policy/legislation, new initiatives and resourcing)?

Some aspects of the delivery and implementation of the new forms of local spatial plans in England have already been touched upon in recent research (e.g. Nadin, 
2006; Terence O'Rourke and UWE, 2008). However, these previous studies tend to cover, in fairly broad terms, a variety of aspects of the plan-making process leading up to the successful adoption of a plan. What had been lacking was a more focused study looking primarily at matters relating to the implementation and delivery of infrastructure since the 2004 reforms. This paper draws on a specific component (thematic study 5) of the wider SPiP study (see Baker et al., 2008) which was intended to address this research gap and, in doing so, employed a number of related methodological components:

I. A review and analysis of the various relevant government policy statements and previous research to clarify the concepts behind the delivery of spatial plans and their role in local infrastructure provision.

2. A documentary/web-based review of the limited number of CSs and AAPs that had been adopted by the time the research was undertaken (June 2007). These types of development plan documents were chosen as the main focus because they were likely to have related infrastructure requirements in terms of their implementation.

3. Four case studies, drawn from those local authorities investigated in the second research component and the wider SPiP project, which cover a range of planning contexts where infrastructure delivery was identified as a significant issue.

4. Two half-day discussion workshops, held in the summer of 2007, involving a number of invited 'experts' and 'key players' at the national level to amplify understanding of issues related to spatial plan delivery, including current experiences and potential innovative approaches and good practice.

\section{Documentary analysis of LDF infrastructure content}

As part of the wider SPiP research, relevant LDF documents from the study's case study authorities had already been evaluated against a template based around a set of criteria chosen for their relevance to the broad concept of what was meant by spatial planning under the 2004 reforms. Four of these evaluation criteria explicitly addressed issues relating to delivery and implementation, encompassing issues related to (i) evidence of joint ownership of proposals and/or working with other delivery agents; (ii) the use of a range of incentives and mechanisms to meet infrastructure requirements; (iii) the resources required to deliver infrastructure proposals and the proposed sources of funding to achieve this; and (iv) an explanation of any phasing and investment programmes. This evaluation revealed a rather mixed picture in terms of the quality of emerging LDF content in respect of infrastructure delivery and implementation, with only between two and six of the i 8 documents examined addressing each of these criteria in ways that were judged as 'very good' or 'good', 
whereas between 7 and I2 (38-65 per cent) of the documents were judged to have addressed these criteria 'poorly' or not at all.

Common weaknesses included a failure to provide sufficient detail on the infrastructure requirements of the plan; a lack of identification of the agencies responsible to deliver specific projects or proposals or who the key partners might be; insufficient consideration (or evidence) that the key partners were willing or able to take responsibility for delivering relevant infrastructure requirements of the LDF; insufficient consideration of the existing plans, strategies and expenditure commitments of the key partners; and the inclusion of overly 'aspirational' or unrealistic policies and proposals. Some good practice pointers could also be picked out. These include LDF documents that provide details of the agencies responsible for delivery of plan policies or proposals; those that provide sufficient evidence of joint ownership of such proposals and the commitment of partners to their delivery; and those that provide information on the means of funding available (such as developer contributions in respect of particular sites).

These few examples of good practice notwithstanding, the evidence from the wider SPiP evaluation suggested that local authorities are struggling to get to grips with the issue of infrastructure delivery. However, the subsequent, more in-depth, documentary analysis of the I2 CSs and two AAPs adopted by June 2007 (and their associated inspectors' reports) was somewhat more positive, revealing a number of positive lessons and 'good practice' examples, in terms of the ways in which the authorities are addressing delivery issues in their LDF documents, and the approaches they are adopting in order to do so:

- Several authorities explicitly emphasised the importance of taking a partnership approach to infrastructure delivery and were actively working with a range of delivery partners to achieve the policies and proposals set out in their plans. Examples included the Plymouth, Horsham and South Cambridgeshire core strategies; the Hampshire Minerals and Waste strategy and the Biddulph Town Centre AAP.

- A variety of mechanisms were being employed to achieve this, ranging from longerstanding, pre-LDF partnership arrangements in South Cambridgeshire to the establishment of new vehicles for partnership such as Project Integra (Hampshire) or the use of existing town centre management arrangements and the potential creation of a limited company in respect of Biddulph Town Centre.

- Important linkages with LSPs were highlighted in some areas, notably in the Plymouth and Hambleton core strategies and the Biddulph Town Centre AAP.

- Agreements or 'statements of commitment' with individual delivery partners had been secured in relation to some plans, including the Redcar and Cleveland Core Strategy and the Walker Riverside AAP.

- The relationship between the LDF and other strategies at the local and regional 
level, in terms of strategy coordination over infrastructure delivery, was set out in the Hambleton, South Cambridgeshire and Plymouth core strategies and the Hampshire Minerals and Waste strategy.

- The importance of community involvement and consultation with key stakeholders was highlighted in South Cambridgeshire, Hambleton, Hampshire and Plymouth.

- Several LDF documents set out clear statements relating to the delivery of infrastructure requirements, and the broader implementation of policies, via the identification of responsible agencies and the setting of targets for monitoring purposes etc. Examples included Redcar and Cleveland's Implementation Plan; the arrangements for monitoring and delivery set out in the Hambleton Core Strategy; Hampshire's monitoring plan; and the revised Core Strategy for Mid-Devon.

- Various mechanisms for the funding of infrastructure delivery were considered, including the use of developer contributions in Biddulph Town Centre and the use of the Council's own land sale receipts in Walker Riverside.

\section{Case studies}

Several of the issues identified in the documentary analyses were examined further through four case studies. These were drawn from the authorities investigated in the documentary analysis and/or the wider SPiP study in such a way as to cover a crosssection of spatial planning contexts where infrastructure delivery had been identified as a potentially significant issue. Each case study involved web-based/documentary analysis and a number of interviews (around six per case) with local authority representatives and stakeholders involved in the delivery of infrastructure requirements related to the LDF (e.g. LSP, housing, transport, and water providers).

The four chosen case studies covered:

- a local authority within a nationally designated growth area (Ashford [A]);

- an urban metropolitan authority with a focus on regeneration (Liverpool [L]);

- a mixed urban/rural authority with an adopted core strategy (CS) which addresses local infrastructure needs (Redcar and Cleveland [RC]);

- a more localised area, covered by an AAP with associated infrastructure requirements (Walker Riverside AAP, Newcastle upon Tyne [N]).

The main findings from each of these case studies are described below.

\section{Ashford}

Ashford is a mixed urban and rural borough in the County of Kent with a rapidly growing population of around iı2,ooo. Its main town has long been at the hub of 
several rail and communication networks providing links to London but it now also benefits from fast links through Eurotunnel to Paris and other European destinations. In March 200I, Ashford was identified by the government as one of four growth areas within the South East. The Ashford case thus allowed for a more in-depth study of how LDF infrastructure requirements are being handled in such a nationally identified 'growth area' context with significant levels of planned new residential and employment development on several large sites within the main town and in the form of significant urban extensions. These are associated with high levels of required infrastructure provision, including major highway works as well as other health, education and community facilities.

As the local authority of a growth area, Ashford Council is able to operate in the context of relatively high levels of public sector and government commitment to the delivery of its LDF vision. A special purposes/partnership agency (Ashford's Future) has been established and partnership working between this agency (incorporating the Borough Council, the Department for Communities and Local Government, the Government Office for the South East, the Environment Agency, Kent County Council, English Partnerships, the Learning and Skills Council, the Regional Development Agency and the Regional Assembly for the South East of England) and a number of key private sector developers has resulted in the emergence, over the last few years, of the only tangible example of a local infrastructure group encountered in the course of the research.

The authority had nevertheless encountered difficulties in ensuring the necessary degree of developer involvement and contribution to infrastructure provision. In particular, the creation of a new motorway junction (IOa) on the M20 motorway was identified as a requirement given the level of proposed development. However, responsibility for undertaking this work could not be easily assigned as several developers were responsible for different sites and these developers also argued that the necessary revenue streams for the junction improvement could only be generated by proceeding with the development proposals first - a solution that was considered unacceptable by the Council. Negotiations between individual developers and the Council were anecdotally said to have been going on for almost five years until one company (unnamed by interviewees) agreed to finance the development of the motorway junction before being reimbursed of some of the costs by fellow developers, in some cases through a redistribution of section Io6 receipts.

Partly in response to these earlier problems in securing developer contributions, the Ashford CS sets out specific policies relating to a 'strategic tariff' through which it is hoped to support a contractual audit trail relating to specific commitments. Under the proposal, pooled public funds would be used to finance required infrastructure projects and would be subsequently refunded through a pre-defined strategic tariff paid by the developers. The CS was undergoing examination at the time the case study 
research was undertaken and, while interviewees were understandably quite guarded, it was suggested that issues relating to infrastructure provision and the policies in respect of the proposed strategic tariff would be central to the examination.

\section{Liverpool}

Liverpool is a well-known port city in the North West of England with a population of around 435, ooo set within the wider Merseyside City Region. The area suffered severe economic restructuring in the I970s and Ig8os with the rapid decline of its traditional manufacturing and maritime industries, but recovered somewhat from the I990s onwards. The city centre and waterfront in particular have been the focus of several large-scale development projects in recent years, culminating in the 'Liverpool One' retail and leisure development which opened its first phase in 2008. Parts of the city's historic core and waterfront have been inscribed as a World Heritage Site by UNESCO and the city was designated European Capital of Culture in 2008.

Although also operating in a complex institutional arena with a plethora of publicand private-sector organisations and agencies with spatial planning and development interests, Liverpool contrasted with Ashford in its focus on regeneration and the relatively powerful position of several major landowners. There is significant development pressure associated with high-profile city-centre and riverside sites including large-scale retail and leisure developments (Paradise Street and King's Waterfront); a cruise liner facility; the Pier Head canal development; office developments in the commercial district; and the redevelopment of Lime Street railway station. According to some interviewees, this level of development is placing severe demands on the existing infrastructure, ranging from sewerage to capacity issues on the city's underground network.

As might be expected in a metropolitan context, Liverpool City Council sits within a congested institutional setting with a host of regeneration and economic development agencies, the most significant of which include the Liverpool Land Development Company (LLDC), Business Liverpool and Liverpool Vision, as well as an array of private developers, energy and utility companies that serve the city centre. However, there is currently little evidence of coordination of strategy development between all these delivery partners, or of any comprehensive analysis of infrastructure needs except in relation to the LLDC's research in relation to land in the Northshore area alongside the Mersey Estuary, primarily under the ownership of one major landowner, Peel Holdings. Partnership between these main players and the LDF team appeared somewhat piecemeal and episodic - a situation not helped by the tendency for the main landowners and developers to interact primarily with the political and administrative leadership of the City Council (i.e. the Chief Executive's Office) rather than with the planning department. In the view of some of the interviewees, this 
situation was exacerbated by the relatively privileged and uncontested position of some utility companies as the sole provider of some facilities in the city centre. It was suggested that these circumstances do not provide an incentive for such providers to engage in strategic forward planning.

Moreover, there was little evidence to suggest that agencies external to the City Council have been integral to the plan-making (LDF) process in relation to identifying infrastructure requirements. Indeed, engagement with some agencies was said to have been inhibited by the partners' unwillingness to get involved in the LDF process; for example, Natural England were said to have been difficult to engage with. More positively, links with Liverpool First, the LSP, appeared somewhat stronger, though these too had been inhibited by the fact that it had undergone a prolonged period of upheaval and staff turnover. No 'infrastructure plan' had yet been prepared as part of the LDF process although, in any event, the Council's LDF work was still at too early a stage to speculate with any confidence on how this situation might develop in the future.

\section{Redcar and Cleveland}

Redcar and Cleveland Council is a unitary authority in the North East of England with a population of just under I40,00o. The Borough includes coastal towns such as Redcar and Saltburn and the market town of Guisborough on the edge of the North York Moors National Park, as well as large steel and chemical industrial complexes and urban settlements in the more eastern parts of the Borough that are strongly connected with the wider Teesside City Region.

In contrast to the Liverpool case, Redcar and Cleveland provided an excellent example of an adopted CS which has, as a key component, an 'Implementation Plan' which cross-references policy commitments outlined in the CS with desired outcomes, indictors for monitoring implementation, the mechanism for delivery, and the lead agencies involved. Mechanisms for delivery identified in the Implementation Plan included a range of further development plan documents and action area plans targeted at the local scale, the determination of planning applications and a range of additional strategies aimed at specific policy issues. This approach was commended by the inspector following the examination of the C.S.

The developments of partnership approaches, and the consideration of crossboundary issues, were also positive aspects identified in relation to this case. The interviewees commented that the CS takes account of a range of spatial scales but has a specific focus on the sub-regional and local levels. The LDF team leader commented that it is intended to link the two scales in order to help address crossboundary linkages, particularly in relation to the delivery of services and in enhancing connectivity between urban areas and transport hubs such as airports and ports. The 
infrastructure priorities in the CS reflect existing priorities that have been ongoing in the Borough.

The infrastructure requirements in the CS are being delivered through a partnership approach led by the local authority planning team. Partners from within the local authority have formed a steering group which includes representatives from planning, housing, social services, education, health and the LSP. External partners have engaged with the local authority steering group through workshops, meetings and statutory consultation on draft documents from an early stage in the LDF process. Relationships between the LDF and the LSP are also developing. There seemed to be a consensus that the process had been relatively smooth and that few difficulties had been encountered. However, identified challenges include some difficulties in engaging developers, and subsequently keeping them involved. There are no plans to set up a specific local infrastructure group, partly because it was seen as unnecessary since other mechanisms (particularly the steering group) had the required capacity to coordinate infrastructure delivery. However, there are plans to set up a section ro6 'pot' to help fund strategic infrastructure priorities.

There was a general consensus among interviewees that the synchronisation of planning and infrastructure delivery had been problematic. Individual local authority departments were sometimes delivering their own infrastructure priorities ahead of the preparation of a spatial plan and there were some frustrations over the length of the statutory plan preparation process. It was also suggested that the prioritisation of government funding, and a general uncertainty surrounding longer-term funding, are real obstacles to effective infrastructure delivery.

\section{Walker Riverside}

Walker Riverside is the location of an ongoing $£ 45^{\circ}$ million regeneration project in a deprived part of the City of Newcastle upon Tyne in the North East of England. It thus provided an opportunity to consider more closely issues relating to infrastructure delivery at the local scale, in relation to an adopted AAP with a strong community regeneration focus targeted at two deprived neighbourhoods. The key infrastructure requirements identified in the plan include major new shopping areas to provide functional services to these communities. The plan also looks to develop a hub at the heart of the two communities including a new leisure centre, primary school and shopping facilities.

To achieve this, the fostering of effective partnership working is considered essential. The main vehicle for such partnership working has been the establishment of the Walker Riverside Board on which the key players, both within and external to the Council, have been invited to sit. As well as Council representatives, the Board's steering group included members drawn from the North East Development Agency, 
English Partnerships, the Housing Corporation, the local housing market renewal pathfinder, two development companies and community and voluntary groups. The Board meets on a monthly basis to discuss the development priorities of the area. In addition to meeting statutory consultation requirements, this partnership approach was also seen as beneficial in bringing together the diverse skills that were needed to deliver particular aspects of the proposals and the financial resources needed for delivery.

Nevertheless, while there was widespread consensus that the engagement of partners responsible for the delivery of infrastructure is necessary, a number of interviewees commented that this had sometimes been challenging to achieve in practice. Coordination with partners within the Council appears to have been generally more straightforward than with external partners and engaging with the private sector has been somewhat problematic. These concerns were echoed by the regeneration officer responsible for implementing the plan who described the process of engaging all partners as 'a massive uphill struggle' - a perspective that was supported in interviews with other local authority and external partners, who felt that their engagement had been somewhat fragmented, creating problems in coordinating AAP policy objectives with those of partners and agencies.

Although the delivery of the AAP has not been coordinated through mechanisms such as an LAA, extensive consideration has been given to funding mechanisms, including developer contributions, and the Council's own landownership helps control and facilitate developments. Nevertheless, problems of synchronisation with other partners' strategies, priorities and timescales have also proved challenging and some interviewees felt that plan proposals were being held back by a lack of longerterm infrastructure planning by partners or by the relatively low priority afforded to developments in the area by some national agencies, whose main focus was felt by some of the north-east-based interviewees to be on areas in the south related to the nationally designated growth areas and the 2012 Olympics.

\section{Stakeholder and local government perspectives on infra- structure delivery}

The wider governmental context within which the delivery of infrastructure is taking place is one of significant change. The final component of the research - involving two half-day workshops with a number of invited 'experts' and 'key players' at the national level to amplify understanding of issues related to spatial plan delivery, including current experiences and potential innovative approaches and good practice - provided an opportunity to reflect more broadly on issues related to infrastructure delivery and LDF implementation within this complex and rapidly changing context. There was a strong consensus among the participants of the need for local authorities 
to give serious consideration to issues relating to the implementation of their LDF and, in particular, the means by which necessary infrastructure requirements will be delivered, by whom and to what timescales.

A number of participants suggested that perceptions of what is meant by 'infrastructure' are also changing - they used to consist primarily of utilities, flood defences and roads but this has evolved to include a range of social, community and environmental facilities such as enhanced 'green space'. Consequently, workshop participants felt that, in order to facilitate better infrastructure delivery, a broader and more comprehensive conceptualisation of 'infrastructure' is needed. The adoption of spatial planning in the UK has been underpinned by a strong stance from the government that the success of the new system is dependent on a change in culture with regard to the way that those involved in the planning process think and work (Shaw, 2006; Shaw and Lord, 2007). As one participant commented, 'It is impossible to separate this debate from the wider debate on culture change and the difference between land use and spatial planning. Culture change will be pivotal to ensure that all these different ideas about what constitutes infrastructure are taken into account'.

However, some of the participants sounded a note of caution, warning that funding, and the ability of the local authority and other partners to deliver infrastructure, is always going to be constrained so there is a need to avoid a simple 'shopping list' of desired provision which is likely to be unattainable. Participants representing local government identified the need for a long-term funding commitment from government to help local planning authorities in the delivery of infrastructure and felt that such a commitment was currently lacking. The implication is that prioritising between potential infrastructural requirements is essential when preparing most LDF documents. Plans should also give appropriate consideration to the level of risk that some of the required infrastructure will not be forthcoming and consider ways in which this might be mitigated or addressed. As one participant noted, 'the easiest way to "ruin" a plan is to show that the infrastructure goals of the document are undeliverable'. As well as failing to meet the government's tests of soundness, potential delivery partners, stakeholders, local communities and the public are likely to become quickly disillusioned with the new planning system if LDFs are unrealistic and the visions, policies and proposals within them are not delivered.

A number of workshop participants identified possible practical approaches to mitigating 'poor infrastructure plan-making' such as working to budgets and thinking about issues of timing. However, one participant suggested a more innovative approach in which local authorities demand 'Commitment Statements' from partners which could then be made available to planning inspectors as part of the evidence in terms of meeting the test of soundness related to plan delivery. This also raised the issue of putting in place appropriate mechanisms for monitoring whether the necessary infrastructural requirements are subsequently being delivered, and to reconsider (as 
necessary) the prioritisation and subsequent delivery programme. It was accepted that having an evidence base was important to make the case for infrastructure requirements, but participants in the workshops were unclear how far the evidence needs to go in order to be considered sufficient.

Some participants suggested that an infrastructure-specific development plan document (DPD) could be included within the LDF which would outline infrastructure requirements for specific development priorities. However, others suggested that, because infrastructure requirements change with each development, an 'infrastructure programme', agreed jointly with delivery partners and treated as a 'living document' to be amended as appropriate (and thus kept up to date), would be more beneficial. Irrespective of whether either of these options was preferred, there was general agreement that Annual Monitoring Reports (a requirement under the 2004 reforms) were the appropriate vehicle for generating the evidence base to support infrastructure requirements. On a related point, participants also commented that any subsequent changes to the tests of soundness should not add any further unnecessary delays to plan-preparation timescales.

In terms of coordination, it was accepted that a local authority could act as the 'ringmaster', given current institutional and cultural developments in the local government arena which could provide a range of more integrated mechanisms for infrastructure delivery. Links between the local authority and the local strategic partnership are particularly important and there is potential for new and emerging mechanisms such as LAAs, MAAs and 'special purpose vehicles' to provide a means of coordinating activities and funding. However, there is a need for greater understanding of these possibilities, and the complex and rapidly changing context, by both local authorities and other stakeholders. In particular, it would seem from the workshop discussions that a number of the representatives of organisations or agencies probably had little or no real understanding of any of these matters, or possibilities, at present. As one participant succinctly put it, 'isn't this all too complicated ... [developers] just go out and build houses - they don't know what an LSP, an LAA or an MAA is...!'.

Private-sector developers were seen by virtually all participants as having an important role to play in infrastructure delivery. However, the private-sector representatives present argued that local planners need better understanding of the development process and property finance in order to understand what might or might not be possible. From a developer perspective, there were concerns that expectations with respect to infrastructure delivery are often unrealistically high: 'everyone wants infrastructure now, but to pay for it later... that just isn't realistic'. It was recognised that mechanisms such as Planning-Gain Supplement and developer contributions have a potentially important role to play in infrastructure delivery. However, the general consensus was that the private sector, on its own, would not be sufficient for delivering infrastructure. A more committed approach from local authorities to forming partner- 
ships with developers is needed but this has to be worked on as, at present, there often appear to be difficulties in getting developers (and other private-sector agencies) to engage fully in the LDF process.

The participants also highlighted common synchronisation difficulties between the visions and time-horizons of the LDF process and those of the different delivery partners. This has not been helped by the lengthy timescales required, so far, to prepare the first round of LDF outputs, particularly CSs. However, as local planning authorities become more experienced in respect of the reformed system, this should improve. There was also an overall feeling, particularly among local government representatives, that it is important to let the current system 'bed in' and to give local planners sufficient time and resources to develop a working system. Nevertheless, it is also clear that greater understanding of the spatial planning process, and the wider evolution and role of local government, is needed. A continued drive for further culture change among both local planning authorities and their delivery partners thus remains crucial.

\section{Discussion and conclusion}

This paper, and the research study upon which it has drawn, has focused on issues relating to the delivery of infrastructure requirements related to the new LDF process in England. Its importance is evident, as the success of the new LDF process is not simply judged on whether local planning authorities can steer their new-style documents through the statutory procedures to adoption, but rather on whether the resulting policies and proposals make a difference to the quality of places and people's lives. Success or otherwise in terms of implementation and delivery, however measured or evaluated, is crucial if the reformed spatial planning system is to be judged successful (see Berke et al., 2006; HM Treasury, 2007). Through empirical research involving case studies, participant workshops and documentary analysis, this study has built upon, and extended, the research and policy context established by previous academic literature, research and government policy statements.

Although it is generally accepted that implementation gaps are always likely to exist in planning (e.g. Cloke, I987; Filion, I996; Gilg and Kelly, ı997a; I997b; Laurian et al., 2004; Berke et al., 2006), the 2004 reforms were enacted with the intention of creating a quicker, more flexible, and integrated planning system, which the government hoped would help to reduce gaps in implementation and delivery of infrastructure. Sadly, but perhaps not unsurprisingly, the research suggests that there is a significant danger of a continued plan implementation gap associated with the new-style LDFs and that failures to deliver the necessary infrastructure required to meet the policies, proposals and aspirations of these plans lie at the heart of this gap.

Based on the research findings, six steps to better integration and delivery were 
1. Realise the central role of the spatial plan

2. Collaborate with service providers from the start

3. Develop an integrated spatial strategy

4. Identify required levels of infrastructure provision

5. Find the funding for infrastructure

6. Coordinate implementation between partners

Figure 1 The role of local planning authorities in infrastructure delivery: six steps to integration and implementation

Source: Baker, 2008

subsequently identified (Fig. I) and used as the basis of a series of regional workshops involving representatives of local planning authorities and other stakeholders (Baker, 2008). These highlight the vital role of local planning authorities, and LDFs, in planning for the infrastructure requirements necessary to support the implementation of plan policies and proposals. These steps include fully recognising the important role that the LDF has as a vehicle for integrated spatial planning; identifying (and working with) the key delivery partners and stakeholders from the outset; developing, with these partners, an integrated set of spatial planning policies and proposals; identifying the required levels of infrastructure provision needed to realise the plan's objectives, policies and proposals; considering the ways of securing the necessary funding and resources from a variety of potential sources across the private and public sectors; and, finally, taking a leading role in coordinating the subsequent implementation of the plan and monitoring its success (or otherwise). More detailed 'good practice' examples and lessons were identified by the research, from which a number of more practical recommendations can be drawn (see Baker et al., 2008 for more detail).

To begin with, the documentary reviews show that some local authorities still have quite a way to go in adequately considering the means by which necessary infrastructural requirements will be delivered, by whom, and to what timescales. These infrastructure requirements should normally be broadly conceived as embracing all matters necessary for the achievement of LDF policies, proposals and aspirations. For example, the LDF will include policies and proposals relating to the delivery of traditional 'hard' infrastructure such as roads and utilities (Graham and Marvin, I996) but it is recognised that, due to the scope of spatial planning, LDF policies will need to address the delivery of 'soft' infrastructure requirements such as 'green infrastructure' and the provision of a wide range of community services (Ennis, 2003 b).

However, because of resource constraints, 'shopping lists' of desired provision 
that are likely to be unattainable should be avoided, thus making adequate prioritising among potential infrastructural requirements of crucial importance. Local planning authorities also need to avoid common weaknesses encountered in some of the submitted LDF documents, such as a failure to provide sufficient detail of the infrastructure requirements of the plan; a lack of identification of the agencies responsible to deliver specific projects or proposals or who the key partners might be; insufficient consideration (or evidence) that key partners were willing or able to take responsibility for delivering relevant infrastructure requirements of the LDF; insufficient consideration of the existing plans, strategies and expenditure commitments of the key partners; and the inclusion of overly aspirational or unrealistic policies and proposals.

Since much of the necessary infrastructure required to deliver the policies and proposals set out in LDFs will be delivered by other delivery partners, local planning authorities will also need to provide sufficient evidence of joint ownership of infrastructure proposals and of the commitment of such partners to their delivery. Formal agreements with delivery partners should be secured wherever possible through a process of negotiation (Bianco and Adler, 200I; Ennis, 2003a) and such statements will be an important source of evidence in showing that an emerging LDF is 'sound'. In any case, the involvement of key partners from the earliest stages of plan preparation is essential if infrastructure requirements are to be delivered (Burby, 2003).

Once plans are adopted, appropriate mechanisms are needed to pick up quickly on any emerging implementation gaps in terms of infrastructure delivery. Relevant LDF documents should therefore also set out clear statements relating to the delivery of infrastructure requirements, and the broader implementation of policies, through the identification of responsible agencies and the setting of targets for monitoring purposes (Wong et al., 2005). Appropriate mechanisms should be put in place to monitor whether the necessary infrastructural requirements are subsequently being delivered, and to reconsider the prioritisation and subsequent delivery programme as necessary. The annual monitoring report is an obvious vehicle for addressing some of these issues, as might be some form of 'infrastructure programme' which should be agreed jointly with delivery partners as far as possible and treated as a 'living document' to be amended as and when required to keep it up to date.

The adoption of a robust approach, whereby plans and policies are monitored and evaluated, should help to improve the coordination of infrastructure provision and reduce unnecessary delays - but only if the monitoring process is used as a tool for identifying discrepancies between the objectives of the plan, updated national policy goals and the strategic objectives of delivery partners (Webber and Marshall, 2007). It is also important to recognise that, due to the uncertainty of infrastructure financing (Bridges, I99I; Campbell et al., 2000), relevant LDF documents should also give appropriate consideration to the level of risk that some of the required infrastruc- 
ture will not be forthcoming and the ways that this might be mitigated or addressed.

Previous research (UCL and Deloitte, 2007) has already made some recommendations on the potential for alternative and innovative approaches to the delivery of infrastructure. These include improved collaboration between planners and the stakeholders involved in LSPs; the use of new delivery mechanisms (e.g. LAAs and MAAs); and the establishment of local infrastructure programmes and funds, managed by local infrastructure groups to improve coordination of infrastructure delivery and facilitate more effective resource management. More recently, the Planning White Paper (DCLG, 2007a) identifies local authorities as 'ringmasters', coordinating and working with other infrastructure providers and stakeholders, to deliver infrastructure requirements. There is also a need to consider carefully the relationships between the LDF and other strategies at the local and regional level, in terms of strategy coordination over infrastructure delivery (Webber and Marshall, 2007), as well as recognising the importance of community involvement and consultation with key stakeholders on matters related to infrastructure requirements (e.g. McDonald, I989; Lidskog and Soneryd, 2000).

The LSP is intended to 'bring together at a local level the different parts of the public sector as well as the private, business, community and voluntary sectors so that different initiatives and services support each other and work together' (DLTR, 200I, 7). This would seem to suggest that the government is attempting to strengthen the influence of local areas in the delivery of infrastructure after a period of relative local disengagement from the infrastructure delivery process (see Graham and Marvin, I996; Guy et al., I997; Graham, 2000; Ennis, 2003a). Although this is a welcome and much needed development, it remains to be seen as to whether local re-engagement will actually facilitate more efficient infrastructure delivery. This uncertainty arises in light of the fact that some LSPs appear to have been prescribed and directed from above (Rowe, 2006), while other commentators suggest that current political and institutional cultures prevent local government and its partners from operating strategically and innovatively in the development and implementation of plans (TewdwrJones et al., 2006; Coaffee and Headlam, 2008).

Despite the lack of current practice examples encountered in this research, local authorities should nevertheless consider - in line with earlier recommendations of the EPiSP study (UCL and Deloitte, 2007) - working on a more formalised basis with other partners via the establishment of local infrastructure programmes, funds and (management) groups to facilitate improved coordination and delivery of infrastructure provision (Webber and Marshall, 2007). Local authorities should also explore the potential for more integrated mechanisms for infrastructure delivery. Conceiving a local authority's role as a 'ringmaster', coordinating the actions of partners and the delivery of infrastructure requirements flowing from the LDF, can be useful in this context. However, in doing so, it is important not to lose sight of their overall focus 
on 'making better places'. A successful LDF process involves a range of interrelated spatial planning tasks, in generating visions, objectives, alternatives, and selecting a preferred option, as well as mediation, coordination, consultation and negotiation.

A more committed approach to forming partnerships with developers is, however, not always easy to achieve. Local planners often need a better understanding of the development process and property finance in order to understand what might or might not be possible. Current expectations with respect to infrastructure delivery can also sometimes be unrealistically high. Mechanisms such as developer contributions have a significant role to play in infrastructure delivery, but there needs to be careful thought given to alternative ways in which developers can be more readily encouraged to make commitments to fund infrastructure given the possible limitations of existing mechanisms such as planning obligations (see e.g. Campbell et al., 200o). Locally derived mechanisms such as Ashford's 'strategic tariff' might be one way forward.

One clear issue that emerges from all this, highlighted especially at the workshops, is that of a serious divergence between central government expectations of the reformed system and current practice. Indeed, in some cases, even basic knowledge and understanding among potential stakeholders of the intentions of the new system and of wider government agendas appears lacking. There are also synchronisation difficulties identified between the visions and time-horizons of the LDF process and those of delivery partners, which have not been helped by the lengthy timescales seemingly required to prepare the first round of LDF documents. The sheer amount of policy development in the local government and spatial planning fields in recent years has proved extremely difficult to keep pace with. This is especially the case for those delivery partners whose main focus and working environment is not directly linked to local governance. There is thus a need for continuing effort in terms of dissemination, education and, more broadly, further 'culture change' across local government and infrastructure providers if the intentions of the reformed planning system are to be understood, embraced and ultimately put into practice (Shaw and Lord, 2007). In the meantime, there is a strong argument for letting the current system 'bed in', and for local planners to be given sufficient time and resources to develop a working system.

However, the funding of infrastructure remains a key challenge to effective infrastructure delivery. Since this research was conducted, the government has announced its intention not to introduce a Planning-Gain Supplement as previously suggested but, instead, as part of the 2007 Planning Bill, provisions were made for a new Community Infrastructure Levy (CIL) which is intended to establish a way of increasing investment in vital infrastructure (DCLG, 2008b). This will provide local authorities with powers to apply a levy on new developments in their areas to support the delivery of infrastructure.

Interviews with stakeholders in the workshops and in several of the case study authorities suggested that, on their own, the existing mechanisms for generating 
funding (e.g. section Io6 agreements) clearly do not have the capacity to provide the necessary funding and investment to deliver all planned infrastructure requirements. The Ashford case study clearly revealed some of the difficulties and delays involved in obtaining equitable contributions from a number of developers with joint interests in the development of key strategic sites. In this case, such challenges were partly resolved by the introduction of a local 'strategic tariff' which has successfully generated funding for infrastructure by removing the uncertainty surrounding contributions while still retaining incentives to develop. But such experiences also highlight the need for a more strategic funding mechanism to help fill the potential void between infrastructure requirements and current levels of funding generated through existing mechanisms.

The proposed introduction of the CIL might therefore help at the margins as the introduction of a more systematic, standard charge on new developments will help remove the ambiguity that certainly surrounds the current system of developer contributions. However, any lingering hopes of central government that almost all planned infrastructure - from public transport to affordable housing and green infrastructure - can be primarily secured from developer contributions must surely have been blown away in the current recession. Indeed, the latest news is of some councils already scaling down or deferring section ro6 contributions until the economic climate improves (Gillman, 2009). In such circumstances, increased direct state funding of infrastructure requirements is a necessity.

The delivery of infrastructure is often a lengthy and expensive process requiring substantial long-term financial commitments on the part of various key agencies and sectors. Central government and the key national agencies (e.g. the Highways Agency) need to provide a longer-term financial commitment to funding infrastructure, thus providing greater certainty. As well as directly funding infrastructure, such a commitment would then make it easier to get the private sector and other delivery partners to commit their own resources. Local authorities must improve their planmaking practices and raise their game by focusing on what is required to really make a difference to places and people rather than simply hoping to stumble across the finish line with an adopted plan. Developers need to be encouraged, cajoled and, where appropriate, forced by legal agreements, infrastructure levies and broader tax regimes to play their part - and mechanisms need to be firmly in place to make this happen swiftly once economic conditions start to improve. But central government and publicly funded agencies must also look at their own contribution and shift their focus to longer-term horizons and increased direct funding commitments if implementation gaps resulting from failures to secure necessary infrastructure, such as those identified in this paper, are to be filled. It is to be hoped that this will prove possible, as a spatial plan without means of implementation can be no more than just a dream of what might have been possible, and the more visionary aspirations and intentions of 
the new spatial planning reforms in terms of making better places will remain largely unrealised.

\section{References}

Alexander, E. R. (I98I), 'If planning isn't everything, maybe it's something', Town Planning Review, 52, I3 ${ }^{\mathrm{I}-42 .}$

Alexander, E. R. and FAludi, A. (I989), 'Planning and plan implementation: notes on evaluation criteria', Environment and Planning B, 16, 127-40.

alterman, R and hill, м. (I978), 'Implementation of Urban Land Use Plans', fournal of the American Planning Association, 44, 274-85.

BAER, w. (I997), 'General plan evaluation criteria: an approach to making better plans', fournal of the American Planning Association, 63, 329-42.

BAKER, J. (2008), unpublished presentation for the Planning Advisory Service (PAS) Regional Seminars on LDF Delivery and Infrastructure, January and February.

BAKER, M., HINCKS, S., SHAW, D. and LORD, A. (2008), Infrastructure Delivery - Spatial Plans in Practice: Supporting the Reform of Local Planning, London, DCLG.

BARKer, K. (2004), Review of Housing Supply - Delivering Sustainability: Securing our Future Housing Needs, Final Report, London, HMSO.

BARker, k. (2006), Barker Review of Land Use Planning: Final Report-Recommendations, London, HMSO.

Barrett, s. and fudge, c. (I981), Policy and Action, London, Methuen.

BERKE, P., BAGKHURST, M., DAY, M., ERICKSEN, N., LAURIAN, L., CRAWFORD, J. and DIXON, J. (2006), 'What makes plan implementation successful? An evaluation of local plans and implementation practices in New Zealand', Environment and Planning B, 33, 58 I-6oo.

BIANCO, M. J. and ADLER, s. (200I), 'The politics of implementation: the corporatist paradigm applied to the implementation of Oregon's statewide transportation planning rule', fournal of Planning Education and Research, 21, 5-I6.

BRIDGes, s. (I99I), 'A local government perspective on financing infrastructure', fournal of Planning Literature, 6, 202-209.

BURBY, R. (2003), 'Making plans that matter: citizen involvement and government action', Journal of the American Planning Association, 69, 33-49.

BURby, R., MAY, P., BERKe, P., DALTON, L., FRENGH, s. and KAISER, E. (I997), Making Government Plans:

Experiments in Managing Land Use, Baltimore, Johns Hopkins University Press.

CAMPBELl, H., ELlis, H., HENNEBERry, J. and Gladwell, G. (2000), 'Planning obligations, planning

practice and land-use outcomes', Environment and Planning B, 27, 759-75.

CBi and TUG (GONFEDERATION OF BRITISH INDUSTRY and TRADES UNION CONGREss) (200i), Planning for Productivity: A Ten Point Action Plan, London, CBI

cloke, P. (ed.) (I987), Rural Planning: Policy into Action, London, Harper and Row.

COAfFeE, J. and HeAdlam, N. (2008) 'Pragmatic localism uncovered: the search for locally contingent solutions to national reform agendas', Geoforum, 39, I586-99.

DALton, L. (I989), 'The limits of regulation: evidence from local plan implementation in California', Fournal of the American Planning Association, 55, I5 5 -68. 
DGLG (DEPARTMENT FOR COMmunities AND LOGAl GOVERnMent) (2006), Strong and Prosperous Communities: The Local Government White Paper, London, TSO.

DGlg (DePartment for Gommunities And logal government) (2007a), Planning for a Sustainable Future (Planning White Paper) (Cm 7120), London, TSO.

DGLG (DePARTMEnT For Gommunities And LoGal Government) (2007b), Streamlining Local Development Frameworks: Consultation, London, DCLG.

dGlg (Department for Gommunities And logal government) (2008a), Spatial Plans in Practice: Final Report, London, DCLG.

DGLG (DEPARTMENT FOR GOMMUNITIES AND LOGAL GOVERNMENT) (2008b), The Community Infrastructure Levy, London, DCLG.

ENNis, F. (ed.) (2003a), Infrastructure Provision and the Negotiating Process, Aldershot, Ashgate.

ENNIS, F. (2003b), 'Infrastructure provision and the urban environment', in Ennis 2003a, I-I8. faludi, A. (1987), A Decision-centred View of Environmental Planning, Oxford, Pergamon Press.

FILION, P. (I996), 'Metropolitan planning objectives and implementation constraints: planning in a post-Fordist and postmodern age', Environment and Planning A, 28, I637-6o.

FLyvBerG, B. (2007), 'Policy and planning for large infrastructure projects: problems, causes, cures', Environment and Planning $B, \mathbf{3 4}, 578-97$.

friedman, J. (I969), 'Notes on societal action', Journal of the American Institute of Planners, 35, 3II-I8.

GILG, A. W. and KELLY, M. P. (I997a), 'The delivery of planning policy in Great Britain: explaining the implementation gap. New evidence from a case study in rural England', Environment and Planning $C, \mathbf{1 5}, 19-36$.

Gilg, A. W. and kelly, M. P. (I997b), 'Rural planning in practice', Progress in Planning, 47, $75^{-\mathrm{I}} 53$.

Gillman, s. (2009), 'Authorities easing section ro6 terms', Planning, 27 March.

GRAHAm, s. (2000), 'Introduction: cities and infrastructure networks', International fournal of Urban and Regional Research, 24, II4-I9.

graham, s. and marvin, s. (I996), Telecommunications and the City: Electronic Spaces, Urban Places, London, Routledge.

GUY, S., GRAHAM, s. and MARVIN, s. (I997), 'Splintering networks: cities and technical networks in I990s Britain', Urban Studies, 34, I9I-216.

healey, P. (1997), Collaborative Planning: Shaping Places in Fragmented Societies, London, Macmillan.

healey, P., manamara, P., Elson, M. and doak, J. (i988), Land Use Planning and the Mediation of Urban Change, Cambridge, Cambridge University Press.

Hm treasury (2007), Copy of Economic and Fiscal Report and Financial Statement and Budget Report, London, TSO.

JRF (Joseph rowntree foundation) (200i), Planning Delivering the Fundamental Change - $f R F$ Response to the Planning Green Paper (England). Available at http://www.jrf.org.uk/knowledge/ responses/docs/planninggreenpaper.asp (accessed 5 August 2008).

LAURIAN, L., DAY, M., BACKHURST, M., BERKE, P., ERICKSEN, N., GRAWFORD, J., DIXON, J., and CHAPMAN, s. (2004), 'What drives plan implementation? Plans, planning agencies and developers', fournal of Environmental Planning and Management, 47, 555-77. 
LIDSKOG, R. and SONERYD, L. (2000), 'Transport infrastructure investment and environmental impact assessment in Sweden', Environment and Planning A, 32, I465-79.

LYONS, SIR M. (2007), Lyons Inquiry into Local Government, London, TSO.

madonald, G. т. (I989), 'Rural land use planning decisions by bargaining', fournal of Rural Studies, 5, 325-35.

moss, т. (2003), 'Utilities, land-use change, and urban development: brownfield sites as "cold-

spots" of infrastructure networks in Berlin', Environment and Planning A, 35, $5^{\mathrm{I}} \mathrm{I}-29$.

Nadin, v. (2006), Spatial Plans in Practice Literature Review I: The Role and Scope of Spatial Planning,

London, DCLG.

NADIN, v. (2007), 'The emergence of the spatial planning approach in England', Planning Practice and Research, 22, $43^{-62 .}$

NETZER, D. (I992), 'Do we really need a national infrastructure policy?', Fournal of the American

Planning Association, 58, I39-43.

OdPM (OFFICE OF THE DePUTy PRIME Minister) (200I), Planning Green Paper: Delivering a Fundamental Change, London, HMSO.

odPM (office of THE DEPUTy PRIME minister) (2003), Sustainable Communities: Building for the Future, London, TSO.

odPm (office of the DePUty PRIME minister) (2004), Planning Policy Statement 12: Local Development

Frameworks, London, TSO.

OdPM (OFfice Of The DePUTy PRIMe minister) (2005), Planning Policy Statement I: Delivering Sustain-

able Development, London, TSO.

Poutney, м. т. and Kingsbury, P. w. (I983a), 'Aspects of development control, part I: the relationship with local plans', Town Planning Review, 54, I39-54.

POUTNEY, M. T. and KINGSBURY, P. w. (I983b,) 'Aspects of development control, part 2: the applicants view', Town Planning Review, 54, 285-303.

PRessman, J. and wildavsky, A. (1973), Implementation: How Great Expectations in Washington are Dashed in Oakland, Berkeley, CA, University of California Press.

Pressman, J. and wildavsky, A. (i984), Implementation, 3rd edn, Berkeley, CA, University of California Press.

ROWE, M. (2006), 'Abusive partnerships: new forms of governance, new forms of abuse?', International Journal of Sociology and Social Policy, 26, 207-I9.

RozeE, L. (2008), 'How planning can meet the challenges: in praise of Local Development Frameworks', Town Planning Review, 79, 594-622.

RYDIN, y. (2003), Urban and Environmental Planning in the UK, 2nd edn, Aldershot, Macmillan.

TALEN, E. (I996a), 'Do plans get implemented? A review of evaluation in planning', fournal of Planning Literature, וo, 248-59.

TALEN, E. (I996b), 'After the plans: methods to evaluate the implementation success of plans', Fournal of Planning Education and Research, r6, 79-91.

TAYlor, N. (1998), Urban Planning Theory since 1945, London, Sage.

TERENGe o'rourke and uWe (university of the West of ENGLAND) (2008), Spatial Plans in Practice Thematic Study 4: Cross Boundary Working, London, DCLG.

TEWDWR-JONES, M., MORPHET, J. and ALLMENDINGER, P. (2006), 'The contested strategies of local governance: community strategies, development plans and local government modernisa- 
tion', Environment and Planning A, 38, 533-5 ${ }^{\mathrm{I}}$.

shaw, D. (2006), Spatial Plans in Practice Literature Review: Culture Change and Planning, London, DCLG.

SHAW, D. and LORD, A. (2007), 'The cultural turn? Culture change and what it means for spatial planning in England', Planning Practice and Research, 22, 63-78.

ugl (university GOllege london) and Deloitte (2007), Shaping and Delivering Tomorrow's Places: Effective Practice in Spatial Planning, London, RTPI.

WEBBER, C. and MARSHALl, A. (2007), 'Bridging the gap: delivering infrastructure investment in Britain's cities', Journal of Urban Regeneration and Renewal, $\mathbf{1}, 7$-2 I.

vERHAGE, R. and NEEDHAM, B. (2003), 'Financing public facilities in housing projects: a method for understanding negotiating processes', in Ennis, 2003a, 19-38.

Wildavsky, A. (1973), 'If planning is everything, maybe it's nothing', Policy Sciences, 4, I27-53. wOng, C., BAKer, M. and KIDD, s. (2005), Local Development Framework Monitoring: A Good Practice Guide, London, ODPM. 